\title{
Penggunaan Analisis Biplot Untuk Memetakkan Sekolah Dasar Di Kabupaten Minahasa Tenggara Berdasarkan Indikator Stándar Nasional Pendidikan
}

\author{
Djoni Hatidja ${ }^{1 *}$, Lidya I. Momuat ${ }^{2}$ \\ ${ }^{1}$ Program Studi Matematika, Fakultas MIPA, Universitas Sam Ratulangi Manado \\ ${ }^{2}$ Program Studi Kimia, Fakultas MIPA, Universitas Sam Ratulangi Manado \\ *corresponding author email: dhatidja@unsrat.ac.id
}

\begin{abstract}
Abstrak
Jumlah Sekolah Dasar (SD) di Kabupaten Minahasa Tenggara Provinsi Sulawesi Utara yaitu 97 buah. Database yang akurat mengenai mutu pendidikan SD di Kabupaten minahasa Tenggara sampai saat ini belum tersedia. Oleh karena itu, maka perlu dilakukan penelitian untuk memperoleh database mutu pendidikan pada sekolah-sekolah khususnya SD di Kabupaten Minahasa Tenggara (MITRA). Tujuan penelitian ini adalah: 1) mendeskripsikan mutu SD-SD di Kabupaten Minahasa Tenggara berdasarkan indikator standar nasional pendidikan, yaitu: Standar Kompetensi Lulusan, Standar Isi, Standar Proses, Standar Pendidikan dan Tenaga Kependidikan, Standar Sarana dan Prasarana, Standar Pengelolaan, Standar Pembiayaan Pendidikan dan Standar Penilaian Pendidikan (Standar Nasional Pendidikan); 2) melakukan pemetaan kelebihan dan kekurangan masing-masing SD di Kabupaten Minahasa Tenggara berdasarkan indikator standar Nasional Pendidikan dengan menggunakan analisis Biplot.; 3) Membuat model untuk memprediksi Mutu Pendidikan SD di Kab. MITRA. Penelitian ini dilaksanakan dengan mengambil data primer di 30 SD yang berada di Kabupaten Minahasa Tenggara dan data sekunder di Dinas Pendidikan dan Olahraga Kabupaten Minahasa Tenggara. Peubah-peubah yang diamati adalah Standar Kompetensi Lulusan, Standar Isi, Standar Proses, Standar Pendidikan dan Tenaga Kependidikan, Standar Sarana dan Prasarana, Standar Pengelolaan, Standar Pembiayaan Pendidikan dan Standar Penilaian Pendidikan. Data akan dianlisis dengan menggunakan perangkat lunak Minitab 15 dan SAS 9.13. Hasilnya menunjukkan bahwa 30\% Sekolah Dasar (SD) terakreditasi A, 46,67\% terakreditasi B dan yang belum terakreditasi sebesar 23,33\%. SD Negeri 1 Liwutung mempunyai nilai akreditasi tertinggi, yaitu sebesar 91. SD GMIM Ratahan memiliki skor tertinggi pada standar kompetensi lulusan, standar isi dan standar pengelolaan. SD Negeri 1 Mundung memiliki skor tertinggi pada standar isi. SD Negeri 2 Liwutung memiliki skor tertinggi pada standar pendidik dan tenaga kependidikan. Sedangkan SD Negeri 1 Tababo, SD GMIM Bunag, SD Negeri 1 Tondanouw, dan SD Negeri 1 Tombatu memiliki skor tertinggi masing-masing untuk standar proses proses, standar sarana dan prasarana, standar pembiayaan pendidikan serta standar penilaian pendidikan. Model untuk memprediksi nilai akreditasi SD di Kabupaten Minahasa Tenggara adalah: AKRED $=96.206-0.643 \mathrm{X} 1-0.026 \mathrm{X} 2+0.42 \mathrm{X} 3+0.103 \mathrm{X} 4-$ 0.00007 X5 + 0.33 X6 + 0.00005X7 - 3.01 X8.
\end{abstract}

Kata kunci: Analisis Biplot, Sekolah Dasar, Akreditasi Sekolah, Kabupaten Minahasa Tenggara, Standar Nasional Pendidikan

\section{Using Of Biplot Analysis To Map Basic Schools At Southeast Minahasa District Based On Indicators Of National Education Stándards}

\begin{abstract}
The number of Basic Schools (BS) in Southeast Minahasa District of North Sulawesi Province is 97 units. Accurate databases on the quality of Basic Schools in Southeast Minahasa District are not currently available. Therefore, it is necessary to conduct research to obtain database of quality education in basic schools at Southeast Minahasa District. The objectives of this research are: 1) to describe the quality of BS at Southeast Minahasa district based on indicators of national education standards of, i.e. Graduate Competency Standards, Content Standards, process standard, standards of administrative personel and education personel, Infrastructure Standarda, Management Standards, standards of Educational finance and assessment; 2) to map the advantages and disadvantages of BS at Southeast Minahasa district based on indicators of national education standards using Biplot analysis; 3) make a model to predict accreditation of BS at Southeast Minahasa district. This research was conducted by taking primary data in 30 BS located at Southeast Minahasa District and secondary data at Education and Sport Office of South Minahasa District. The variables
\end{abstract}


observed are the Graduate Competency Standards, Content Standards, process standard, standards of administrative personel and education personel, Infrastructure Standarda, Management Standards, standards of Educational finance and assessment. The data will be analyzed using Minitab 15 and SAS 9.13 software. The results show that $30 \%$ of BS are accredited $A, 46.67 \%$ accredited $B$ and those not yet accredited by 23.33\%. Liwutung Public BS 1 has the highest accreditation value, which is 91. GMIM Ratahan BS has the highest score on graduate competency standard, content standard and management standard. Mundung Public BS 1 has the highest score on standard content. Liwutung public BS 2 has the highest score on the standard of educators and education personnel. Tababo public BS 1, GMIM Bunag BS, Tondanouw public BS 1, and Tombatu public BS 1 have the highest score respectively for standards process, standard of facilities and infrastructure, education financing standard and educational assessment standard. Models for predicting of accreditation grades BS at Southeast Minahasa District are: $A K R E D=96.206-0.643 X 1-0.026 X 2+0.42$ $X 3+0.103 X 4-0.00007 X 5+0.33 X 6+0.00005 X 7-3.01 X 8$.

Keywords: Biplot Analysis, Basic Schools, Acreditation of Schools, Southeast Minahasa District, National Education Standards

\section{Pendahuluan}

\subsection{Latar Belakang}

Sejak tahun anggaran 2009, pemerintah telah menerapkan 20\% APBN untuk sektor pendidikan sesuai amanat dari Undang-Undang Dasar 1945. Anggaran yang besar ini diharapkan secara bertahap dapat meningkatkan mutu pendidikan dasar dan menengah sehingga bisa mencapai standar nasional pendidikan.

Sebelum anggaran disalurkan maka pemerintah yaitu Kementrian Pendidikan dan Kebudayaan (KEMDIKBUD) harus mempunyai database yang akurat mengenai mutu pendidikan dari setiap sekolah yang ada di Kabupaten/Kota seluruh Indonesia. Diharapkan dengan database yang akurat, maka bantuan pendidikan dapat tepat sasaran dan tepat penggunaannya.

Hatidja, telah melakukan penelitian mengenai mutu pendidikan Sekolah Menengah Atas (SMA) di Kota Manado dengan menggunakan analisis Biplot. Pada penelitian ini tidak menggunakan delapan 8 (delapan) standar nasional pendidikan namun hanya menggunakan beberapa komponen dari 3 (tiga) standar nasional pendidikan, yaitu standar konmpetensi lulusan, standar sarana dan prasarana serta standar proses. Hasil penelitian ini dapat memetakkan kelebihan dan kekurangan SMA-SMA di Kota Manado berdasarkan 3 standar tersebut [1].

Kabupaten Minahasa Tenggara yang diresmikan pada tanggal 23 Mei 2007 oleh Menteri Dalam Negeri adalah Kabupaten baru di Provinsi Sulawesi Utara, Indonesia merupakan pemekaran dari Kabupaten Minahasa Selatan. Kabupaten ini memiliki 42 ekolah TK, 97 SD dan 19 SMP dan 15 SMA/SMK. Pada usinya yang masih muda dapat dipastikan bahwa, Kabupaten Minahasa Tenggara belum memiliki database yang akurat mengenai mutu pendidikan dari sekolah-sekolah khususnya Sekolah Dasar (SD). Berdasarkan standar kompetensi lulusan, standar isi dan standar proses, SMP SMP di Kabupaten Minahasa Tenggara dapat dikategorikan: 46\% SMP memiliki mutu baik, dan 54\% SMP memiliki mutu yang tidak baik [2]. Namun berdasarkan standar pendidikan dan tenaga kependidikan, standar sarana dan prasarana, standar pengelolaan dan standar pembiayaan pendidikan, SMP SMP di Kabupaten Minahasa Tenggara dapat dikategorikan: 77\% memiliki mutu baik, dan 23\% memiliki mutu yang tidak baik [3]. Kedua hasil di atas dilakukan dengan menggunakan Analisis Biplot.

Hatidja, Purwanto dan Paendong [4]; Sepang, Hatidja dan Langi [5], menyatakan bahwa terdapat 2 SMA dan 2 SMK di Kabupaten MITRA mempunyai mutu yang tidak memenuhi Standar Nasional Pendidikan (SNP). Peubah yang digunakan adalah 8 SNP (Standar Kompetensi Lulusan, Standar Isi, Standar Proses, Standar Tenaga Pendidik dan Tenaga Kependidikan, Standar Sarana dan Prasarana, Standar Pengelolaan, Standar Pembiayaan Pendidikan dan Standar Penilaian Pendidikan)

Untuk mengetahui apakah pendidikan dasar di kabupaten Minahasa Tenggara sudah memenuhi standar nasional pendidikan, maka tentu harus dilakukan kajian yang mendalam mengenai Sekolah Dasar.

Analisis Biplot merupakan salah satu bagian dari analisis peubah ganda (APG) yang dapat menyajikan secara simultan dalam bentuk gambar dua dimensi antara Indikator Standar Nasional Pendidikan (sebagai variabel) dengan SD (sebagai objek). Dengan analisis Biplot kita dapat 
mengetahui kelebihan dan kekurangan masing-masing sekolah berdasarkan 8 indikator standar nasional pendidikan.

Berdasarkan latar belakang tersebut, maka perlu dilakukan penelitian mengenai mutu sekolah-sekolah khususnya SD di Kabupaten Minahasa Tenggara apakah sudah memenuhi standar nasional pendidikan ataukah belum. Dengan penelitian ini, diharapkan Kabupaten Minahasa Tenggara memiliki database yang akurat mengenai mutu SD sehingga bantuan yang akan disalurkan melalui pemerintah maupun swasta dapat tepat sasaran dan tepat guna.

\subsection{Tujuan Penelitian}

Tujuan penelitian ini adalah:

1. Mendeskripsikan Sekolah Dasar (SD) di Kab. Minahasa Tenggara (MITRA) berdasarkan Standar Kompetensi Lulusan, Standar Isi, Standar Proses, Standar Pendidikan dan Tenaga Kependidikan, Standar Sarana dan Prasarana, Standar Pengelolaan, Standar Pembiayaan Pendidikan dan Standar Penilaian Pendidikan.

2. Memetakkan kelebihan dan kekurangan masing-masing SD di Kab. MITRA berdasarkan Standar Kompetensi Lulusan, Standar Isi, Standar Proses, Standar Pendidikan dan Tenaga Kependidikan, Standar Sarana dan Prasarana, Standar Pengelolaan, Standar Pembiayaan Pendidikan dan Standar Penilaian Pendidikan dengan menggunakan analisis Biplot.

3. Membuat model untuk memprediksi Mutu Pendidikan SD di Kab. MITRA.

\section{Tinjauan Pustaka}

\subsection{Standar Nasional Pendidikan}

Standar Nasional Pendidikan adalah kriteria minimal tentang sistem pendidikan di seluruh wilayah hukum Negara Kesatuan Republik Indonesia [6].

Standar Nasional Pendidikan terdiri dari: 1)Standar Kompetensi Lulusan; 2)Standar Isi; 3)Standar Proses; 4)Standar Pendidikan dan Tenaga Kependidikan; 5) Standar Sarana dan Prasarana; 6) Standar Pengelolaan; 7)Standar Pembiayaan Pendidikan; dan 8)Standar Penilaian Pendidikan [6].

Standar Nasional Pendidikan berfungsi sebagai dasar dalam perencanaan, pelaksanaan, pengawasan pendidikan dalam rangka mewujudkan pendidikan nasional yang bermutu. Sedangkan tujuan Standar Nasional Pendidikan adalah menjamin mutu pendidikan nasional dalam rangka mencerdaskan kehidupan bangsa dan membentuk watak serta peradaban bangsa yang bermartabat. Standar Nasional Pendidikan disempurnakan secara terencana, terarah, dan berkelanjutan sesuai dengan tuntutan perubahan kehidupan lokal, nasional, dan global [6].

\subsection{Analisis Deskripsi}

Beberapa ahli mengatakan bahwa analisis multivariat adalah hubungan antara atau diantara lebih dari dua variabel atau peubah. Tujuan analisis multivariat adalah mengukur, menerangkan dan memprediksi tingkat relasi di antara variat-variat. Jadi, karakter multivariat tidak sekedar berada pada jumlah variabel atau observasi yang dilibatkan dalam analisis tetapi juga pada kombinasi antar variat. Variat adalah kombinasi linier variabel-variabel yang memiliki bobot yang penentuannya dilakukan secara empiris [7].

Analisis multivariat lebih banyak menekankan pada metode-metode statistik yang bersifat menggambarkan dan menganalisis data-data multivariat. Cara penggambaran data tersebut sebagian besar disajikan dalam bentuk gambar atau grafik. Dengan demikian analisis multivariat sebenarnya merupakan bagian dari statistika deskripsi [8].

\subsection{Analisis Biplot}

Biplot dipelopori oleh Gabriel dan didasarkan pada konsep penguraian nilai singular (Singular Value Decompotion, SVD). Menurut Dillon dan Goldstein [9], SVD mengorientasikan kembali sumbu koordinat sehingga membuat data matriks lebih mengikuti untuk mendekatkan diri terhadap pola yang dibuat dari titik matriks itu sendiri. Dalam hal ini SVD membantu untuk memahami struktur data matriks secara lebih baik. Misalkan suatu matriks data $X$ berpangkat $r$ 
berukuran $(n \times p)$ yang berisi $n$ pengamatan dan $p$ peubah dikoreksi terhadap nilai rataannya, maka matriks tersebut dapat dituliskan menjadi:

$$
X=U L A
$$

dengan $U$ dan $A$ masing-masing matriks berukuran (nxp) dan (pxr) sehingga $U^{\prime} U=A^{\prime} A=I_{r}$ (matriks identitas berdimensi $r$ ). $L$ adalah matriks diagonal berukuran $(r x r)$ yang unsur-unsur diagonalnya merupakan akar pangkat dua dari akar ciri $X^{\prime} X$ sehingga $\sqrt{\lambda_{1}} \geq \sqrt{\lambda_{2}} \geq \ldots \geq \sqrt{\lambda_{r}}$. Unsur-unsur diagonal dari matriks $L$ disebut nilai singular matriks $X$. Kolom-kolom matriks $U$ terdiri dari $r$ vektor ciri dari matriks $X^{\prime} X$. Kolom-kolom matriks $U$ disebut vektor singular kolom matriks $X$ dalam ruang berdimensi $n$. Kolom-kolom matriks $A$ terdiri dari $r$ vektor ciri dari matriks $X^{\prime} X$ yang berpadanan dengan akar ciri $\lambda$. Kolom-kolom matriks $A$ disebut vektor singular baris matriks $X$ dalam ruang berdimensi $p$. Berdasarkan kaidah penguraian nilai singular, persamaan (1) dapat diuraikan menjadi:

$$
X=U L^{\alpha} L^{1-\alpha} A^{\prime}
$$

untuk $0 \leq \alpha \leq 1$, jika definisikan $G=U L^{\alpha}$ dan $H^{\prime}=L^{1-\alpha} A^{\prime}$, persamaan (2) dapat ditulis[10]:

$$
X=G H
$$

Maka unsur ke-(ij) matriks $X$ dapat dituliskan sebagai berikut :

$$
\begin{aligned}
& X_{i j}=g_{i} h_{j} \\
& i=1,2,3, \ldots, n ; j=1,2,3, \ldots, p
\end{aligned}
$$

Jika $X$ berpangkat dua, maka vektor pengaruh baris $g_{i}$ dan vektor pengaruh kolom $h_{j}$ dapat digambarkan dalam ruang berdimensi dua. Sedangkan matriks $X$ yang berpangkat lebih dari dua dapat didekati dengan matriks berpangkat dua, sehingga persamaan (4) dapat ditulis menjadi:

$$
{ }_{2} X_{i j}=g_{i}{ }^{*} h_{j} *
$$

dengan masing-masing $g_{i} *$ dan $h_{j}^{*}$ mengandung 2 unsur pertama vektor $g_{i}$ dan $h_{j}$. Dengan pendekatan tersebut maka matriks $X$ dapat disajikan dalam ruang berdimensi dua.

Nilai $\alpha$ yang digunakan bersifat sembarang pada interval $0 \leq \alpha \leq 1$. Pengambilan nilai ekstrim $\alpha=0$ dan $\alpha=1$ berguna untuk mempermudah interpretasi biplot [11]. Apabila nilai $\alpha=0$ maka $G=U$ dan $H=A L$, sehingga diperoleh persamaan :

$$
X^{\prime} X=H H^{\prime}
$$

Karena $X^{\prime} X=H H^{\prime}=(n-1) S$ maka hasil kali $h_{j}{ }^{\prime} h_{k}$ akan sama dengan $(n-1)$ kali peragam $S_{j k}$ dan $h_{j}{ }^{\prime} h_{k}$ menggambarkan keragaman peubah ke- $k$. Korelasi antara peubah ke- $j$ dan ke- $k$ ditunjukkan oleh kosinus sudut antara vektor $h_{j}$ dan $h_{k}$ [11]. Jarak Euclid antara objek pengamatan ke- $h$ dan ke- $i$ dalam biplot sebanding dengan jarak Mahalanobis antara pengamatan ke- $h$ dan ke- $i$.

Pengambilan nilai $\alpha=1$ akan menghasilkan $G=U L$ dan $H=A$ sehingga didapatkan:

$$
X^{\prime} X=G G^{\prime}
$$

Pada keadaan ini jarak Euclid antara $g_{h}$ dan $g_{i}$ akan sama dengan jarak Euclid antara $x_{h}$ dan $x_{i}$. Selain itu vektor pengaruh baris ke- $i$ sama dengan skor komponen utama untuk individu ke- $i$ dari hasil analisis komponen utama. Hal ini dapat dijelaskan secara aljabar, karena $G=U L$ sehingga unsur ke- $k$ dari $g_{i}$ adalah $u_{i k} \sqrt{\lambda_{k}}=Z_{i k}$ yang merupakan skor komponen utama ke- $k$ dari pengamatan ke$i$, dari $H=A$ diperoleh bahwa vektor pengaruh lajur $h_{j}$ sama dengan $a_{j}$, yaitu vektor pembobot peubah ke- $j$ pada komponen utama.

Terdapat empat hal penting yang bisa didperoleh dari tampilan bipot, yaitu:

1. Kedekatan antar objek, informasi ini bisa dijadikan panduan objek mana yang memiliki kemiripan karakteristik dengan objek tertentu. Dua objek dengan karakteristik yang sama akan digambarkan sebagai dua titik yang posisinya saling berdekatan.

2. Keragaman peubah, informasi ini digunakan untuk melihat apakah ada peubah tertentu yang nilainya hampir sama semuanya untuk setiap objek, atau sebaliknya bahwa nilai dari setiap objek ada yang sangat besar dan ada juga yang sangat kecil. Dengan adanya informasi ini, bisa diperkirakan pada peubah mana strategi tertentu harus ditingkatkan, atau sebaliknya. Dalam biplot, peubah dengan keragaman kecil digambarkan sebagai vektor yang pendek sedangkan peubah yang ragamnya besar digambarkan sebagai vektor yang panjang. 
3. Hubungan (korelasi antar peubah), informasi ini bisa digunakan untuk menilai bagaimana peubah yang satu mempengaruhi/dipengaruhi peubah yang lain. Dengan menggunakan biplot, peubah akan digambarkan sebagai garis berarah. Dua peubah yang memiliki korelasi positif tinggi akan digambarkan sebagai dua buah garis dengan arah yang sama, atau membentuk sudut lancip. Sementara itu, dua peubah yang memiliki korelasi negatif tinggi akan digambarkan dalam bentuk dua garis dengan arah yang berlawanan, atau membentuk sudut tumpul, sedangkan dua peubah yang tidak berkorelasi akan digambarkan dalam bentuk dua garis dengan sudut mendekati $90^{\circ}$ (siku-siku).

4. Nilai peubah pada suatu objek, informasi ini bisa digunakan untuk melihat keunggulan dari setiap objek. Objek yang terletak searah dengan arah dari suatu peubah, dikatakan bahwa pada objek tersebut nilainya di atas rata-rata. Sebaliknya, jika objek lain terletak berlawanan dengan arah dari peubah tersebut, maka objek tersebut memiliki nilai di bawah rata-rata. Objek yang hampir ada di tengah-tengah, memiliki nilai dekat dengan rata-rata [12].

Keakuratan dari biplot dalam menerangkan tingkat keragaman dari matriks data asal dirumuskan sebagai berikut:

$$
\rho=\frac{\left(\lambda_{1}+\lambda_{2}\right)}{\sum_{\mathrm{k}=1}^{\mathrm{p}} \lambda_{\mathrm{k}}}
$$

dimana : $\lambda_{1}=$ akar ciri terbesar pertama; $\lambda_{2}=$ akar ciri terbesar kedua; $\lambda_{\mathrm{k}}=$ akar ciri terbesar ke-k; $\rho=$ tingkat keakuratan. Jika $\rho$ semakin mendekati nilai satu maka biplot yang diperoleh dari matriks pendekatan berpangkat dua akan memberikan penyajian yang semakin baik mengenai informasiinformasi yang terdapat pada data sebenarnya [13].

\subsection{Regresi Linier Berganda}

Menurut Myers [14] persamaan regresi linier berganda adalah:

$$
\begin{aligned}
& \mathrm{Yi}=\beta_{0}+\beta_{1} \mathrm{X}_{1 \mathrm{i}}+\beta_{2} \mathrm{X}_{2 \mathrm{i}}+\cdots+\beta_{\mathrm{k}} \mathrm{X}_{\mathrm{ki}}+\varepsilon_{\mathrm{i}} \quad(\mathrm{i}=1,2, \ldots, \mathrm{n}) \\
& \mathrm{k}=\text { Jumlah variabel bebas, } \quad \mathrm{p}=\text { Jumlah parameter }
\end{aligned}
$$

Dalam notasi matriks dapat ditulis:

$$
\mathrm{Y}=\mathrm{X} \beta+\varepsilon \text {, dimana: }
$$

$$
\mathrm{Y}=\left[\begin{array}{c}
y_{1} \\
y_{2} \\
\vdots \\
y_{n}
\end{array}\right] \quad \mathrm{X}=\left[\begin{array}{ccccc}
1 & x_{11} & x_{21} & \cdots & x_{k 1} \\
1 & x_{12} & x_{22} & \cdots & x_{k 2} \\
\vdots & \vdots & \vdots & \ddots & \vdots \\
1 & x_{1 n} & x_{2 n} & \cdots & x_{k n}
\end{array}\right] \quad \beta=\left[\begin{array}{c}
\beta_{0} \\
\beta_{1} \\
\beta_{2} \\
\vdots \\
\beta_{k}
\end{array}\right] \quad \varepsilon=\left[\begin{array}{c}
\varepsilon_{1} \\
\varepsilon_{2} \\
\vdots \\
\varepsilon_{n}
\end{array}\right]
$$

Asumsi yang mendasari model di atas adalah, yaitu:

1) $\varepsilon_{\mathrm{i}}$ menyebar saling bebas mengikuti sebaran normal $\left(0, \sigma^{2}\right)$;2) $\varepsilon_{\mathrm{i}}$ memiliki ragam homogen atau disebut juga tidak ada masalah heterokedastis; 3 ) Tidak ada hubungan antara peubah $\mathrm{X}$ atau sering disebut tidak ada masalah kolinier; dan 4) $\varepsilon_{\mathrm{i}}$ bebas terhadap peubah X.

Untuk menentukan koefisien regresi dapat digunakan Metode Kuadrat Terkecil yang merupakan estimator linier tak bias terbaik. Persamaan normal kuadrat terkecil adalah [14]:

$$
\left(X^{\prime} X\right) b=X^{\prime} Y ; \quad b=\left(X^{\prime} X\right)^{-1} X^{\prime} Y
$$

dengan,

$$
X^{\prime} X=\left[\begin{array}{ccccc}
n & \sum X_{1 i} & \sum X_{2 i} & \cdots & \sum X_{k i} \\
\sum X_{1 i} & \sum X_{1 i}^{2} & \sum X_{1 i} X_{2 i} & \cdots & \sum X_{1 i} X_{k i} \\
\vdots & \vdots & \vdots & \ddots & \vdots \\
\sum X_{k i} & \sum X_{k i} X_{1 i} & \sum X_{k i} X_{2 i} & \cdots & \sum X_{k i}^{2}
\end{array}\right] \quad X^{\prime} Y=\left[\begin{array}{c}
\sum Y_{i} \\
\sum X_{i} Y_{i} \\
\vdots \\
\sum X_{k i} Y i
\end{array}\right]
$$




\section{Metode Penelitian}

\subsection{Sumber Data}

Data yang digunakan dalam penelitian ini berasal dari data primer. Data primer diambil pada 30 Sekolah Dasar di Kabupaten Minahasa Tenggara. Data primer yang diambil merupakan sampel dari populasi SD-SD di Kabupaten Minahasa Tenggara. Data tersebut diharapkan mewakili seluruh populasi SD yang berada di kabupaten Minahasa Tenggara. Data sekunder lainnya di Dinas Pendidikan dan Olahraga Kabupaten Minahasa Tenggara.

Pengambilan data dilaksanakan selama 14 hari, yaitu tanggal 7-16 September 2017.

\subsection{Populasi dan Sampel}

Populasi yang dijadikan objek penelitian adalah SD-SD di Kabupaten Minahasa Tenggara, yaitu sebanyak 97 SD. Penelitian ini menggunakan data hasil survei dengan menggunakan teknik pengambilan sampel yakni Purposive Random Sampling atau pengambilan sampel secara sengaja. Besarnya sampel ditentukan dengan rumus sebagai berikut:

$$
n=\frac{N}{N \cdot d^{2}+1}
$$

Dimana: $n=$ jumlah sampel; $N=$ jumlah populasi; $\mathrm{d}=$ presisi yang ditetapkan $(10 \%)$ Besarnya sampel yang diperoleh dari persamaan (8) adalah 30 .

Adapun sekolah-sekolah yang menjadi sampel dari penelitian ini adalah:

\begin{tabular}{|l|l|l|}
\hline - SD INPRES & $\bullet$ SD Negeri 1 Belang & $\bullet$ SD INPRES Kali \\
Tosuraya & $\bullet$ SD GMIM Watuliney & $\bullet$ SD Negeri 1 Tombatu \\
- SDNegeri 2 Ratahan & $\bullet$ SD Negeri Tababo & $\bullet$ SD Negeri 2 Tombatu \\
- SD GMIM Rasi & $\bullet$ SD Negeri 1 Toundanow & $\bullet$ SD Gereja Pantekosta Kali \\
- SD GMIM Ratahan & $\bullet$ SD GMIM Lobu & $\bullet$ SD Negeri Silian Raya \\
- SD Negeri Kecil & $\bullet$ SD GMIM Ranoketang & $\bullet$ SD GMIM 1 Silian \\
Banga & $\bullet$ SD Inpres Liwutung & $\bullet$ SD Negeri 1 Molompar \\
- SD GMIM Bunag & $\bullet$ SD NEGERI 1 Liwutung & $\bullet$ SD INPRES Molompar \\
- SD GMIM & $\bullet$ SD NEGERI 2 Liwutung & $\bullet$ SD Negeri 1 Mundung \\
Tambelang & $\bullet$ SD NEGERI 3 Liwutung & $\bullet$ SD Negeri Maulit \\
\hline
\end{tabular}

\subsection{Peubah atau Variabel Penelitian}

Peubah-peubah yang diamati adalah peubah standar nasional pendidikan yang terdiri dari Standar Kompetensi Lulusan (X1), Standar Isi (X2), Standar Proses (X3), Standar Pendidik dan Tenaga Kependidikan (X4), Standar Sarana dan Prasarana (X5), Standar Pengelolaan (X6), Standar Pembiayaan Pendidikan (X7) dan Standar Penilaian Pendidikan (X8).

\subsection{Metode Analisis}

Metode analisis yang dilakukan dalam penelitian ini ada 2 tahap. Tahap pertama, analisis deskripsi terhadap data asal. Hal ini dilakukan untuk mengetahui gambaran data secara umum. Dalam hal ini, 8 indikator standar nasional pendidikan sebagai sebagai variabel/peubah dan SD sebagai objek pengamatan.

Tahap kedua yaitu analisis Biplot. Adapun langkah langkah analisisnya sebagai berikut: 1) Pemasukan data (matriks data X); 2) Penghitungan matriks koragam/peragam S; 3) Pembentukan Matriks diagonal yang unsur-unsurnya merupakan simpangan baku; 4) Penghitungan matriks korelasi dari matriks X; 5) Standarisasi matriks X; 6) Penguraian matriks X yang telah distandarisasi dengan SVD (Singular Value Decomposition); 7) Penghitungan matriks H=AL dan G=UL; 8) Plot matriks $\mathrm{G}$ dan $\mathrm{H}$ secara tumpang tindih.

Analisis Biplot dilakukan dengan menggunakan perangkat lunak SAS (Statistical Analysis Sistem ) versi 9.13. 


\section{Hasil dan Pembahasan}

\subsection{Nilai Akreditasi Sekolah}

Tabel 10. Jumlah dan Persentasi Grade Akeditasi SD di Kabupaten Minahasa Tenggara

\begin{tabular}{|c|c|c|}
\hline $\begin{array}{c}\text { Grade } \\
\text { Akreditasi }\end{array}$ & $\begin{array}{c}\text { Jumah } \\
\text { SD }\end{array}$ & $\begin{array}{c}\text { Persentasi } \\
(\mathbf{\%})\end{array}$ \\
\hline A & 9 & 30,00 \\
\hline B & 14 & 46,67 \\
\hline Tidak Terakreditasi & 7 & 23,33 \\
\hline Total & 30 & 100 \\
\hline
\end{tabular}

Berdasarkan grade akreditasi, terdapat 9 (30\%) Sekolah Dasar (SD) terakreditasi A, sedangkan terakreditasi B sebesar 14 sekolah (46,67\%) dan yang belum terakreditasi sebesar 23,33\% atau 7 sekolah (Tabel 1). Sekolaha-sekolah yang terkreditasi A adalah: SDN 2 Ratahan, SD GMIM Ratahan, SDN 1 Liwutung, SDN 2 Liwutung, SDN 3 Liwutung, SDN 1 Mundung, SD Gereja Pantekosata Kali, SDN 1 Tombatu dan SD INPRES Kali. Sedangkan Sekolah-sekolah yang tidak terakreditasi adalah: SD GMIM Lobu, SDN Kecil Banga, SD GMIM Bunag, SDN Maulit, SDN 1 Toundanow, SDN Silian Raya dan SD GMIM Tambelang.

Sekolah yang memiliki nilai rata-rata UAN paling tinggi adalah SD GMIM Ratahan dengan nilai 7,90. Hal berarti bahwa sebagian besar siswa SD GMIM Ratahan memahami 79\% materi yang diujikan di UAN. Sekolah yang memiliki nilai rata-rata UAN paling rendah adalah SD Negeri 1 Toundanow dengan nilai 4,25. Hal berarti bahwa sebagian besar siswa SD GMIM Ratahan hanya memahami 42,5\% materi yang diujikan di UAN (Gambar 1).

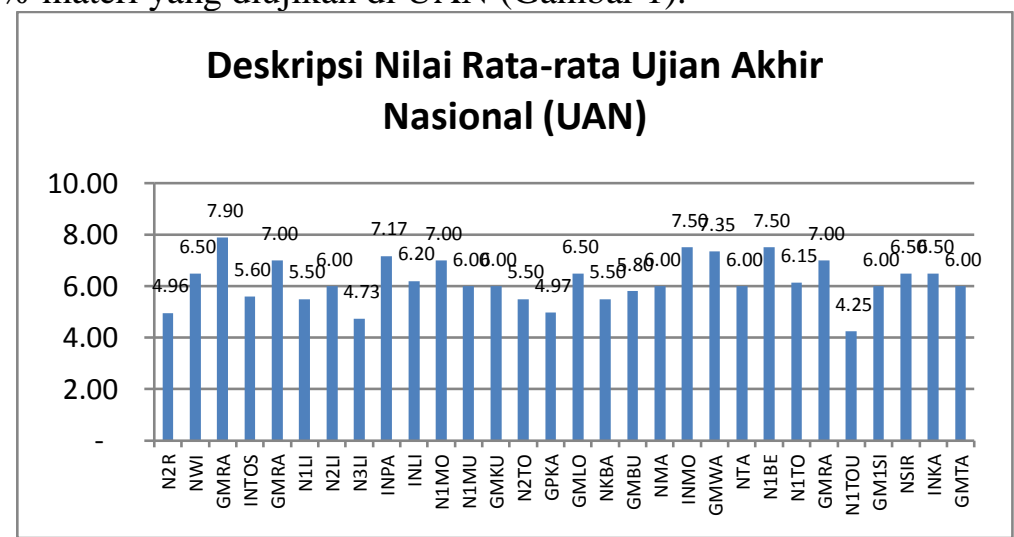

Gambar 1. Deskripsi Nilai Ujian Akhir Nasional (UAN) Sekolah Dasar di Kabupaten Minahasa Tenggara

\subsection{Standar Kompetensi Lulusan}

SD GMIM Ratahan memiliki nilai standar kompetensi lulusan (SKL) tertinggi dengan nilai sebesar 40,34. Sekolah yang mempunyai nilai paling rendah untuk standar kompetensi lulusan adalah SD INPRES Molompar dengan nilai sebesar 30,19 (Gambar 2).

\subsection{Standar Isi}

SD GMIM Ratahan dan SD Negeri Mundung memiliki nilai standar isi (SI) tertinggi dengan nilai 58. Selanjutnya nilai SKL tertinggi kedua adalah SD Negeri 1 Toundanow dengan nilai sebesar 54, sedangkan yang mempunyai nilai paling rendah untuk standar isi adalah SD INPRES Pangu dengan nilai sebesar 20 (Gambar 3). 


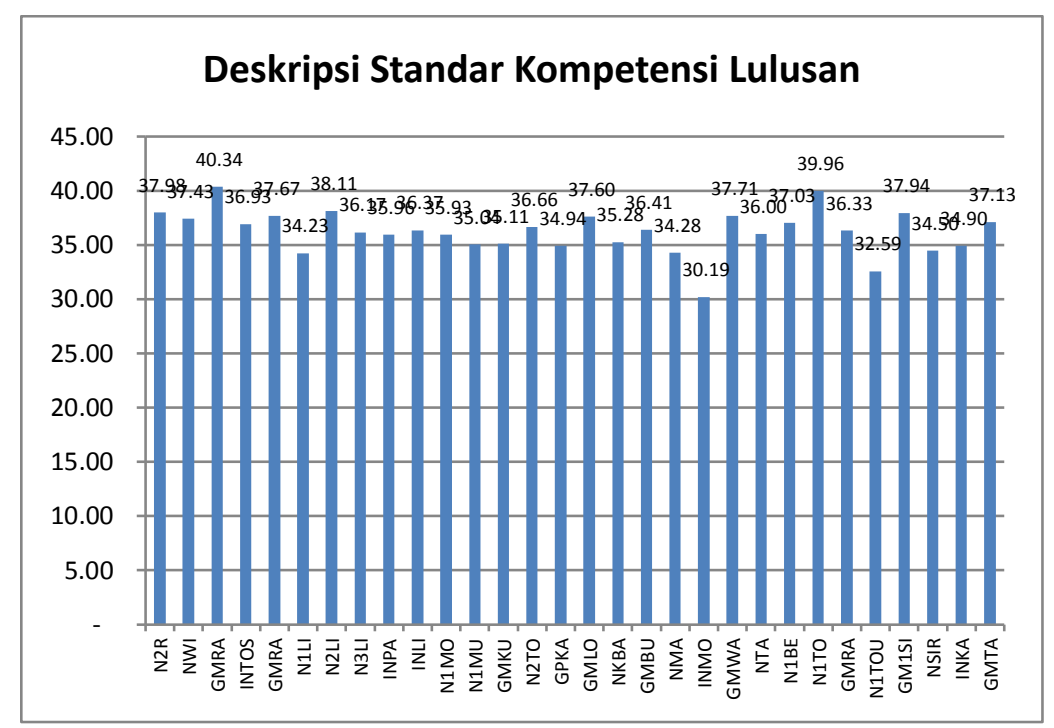

Gambar 2. Deskripsi Standar Kompetensi Lulusan Sekolah Dasar di Kabupaten Minahasa Tenggara

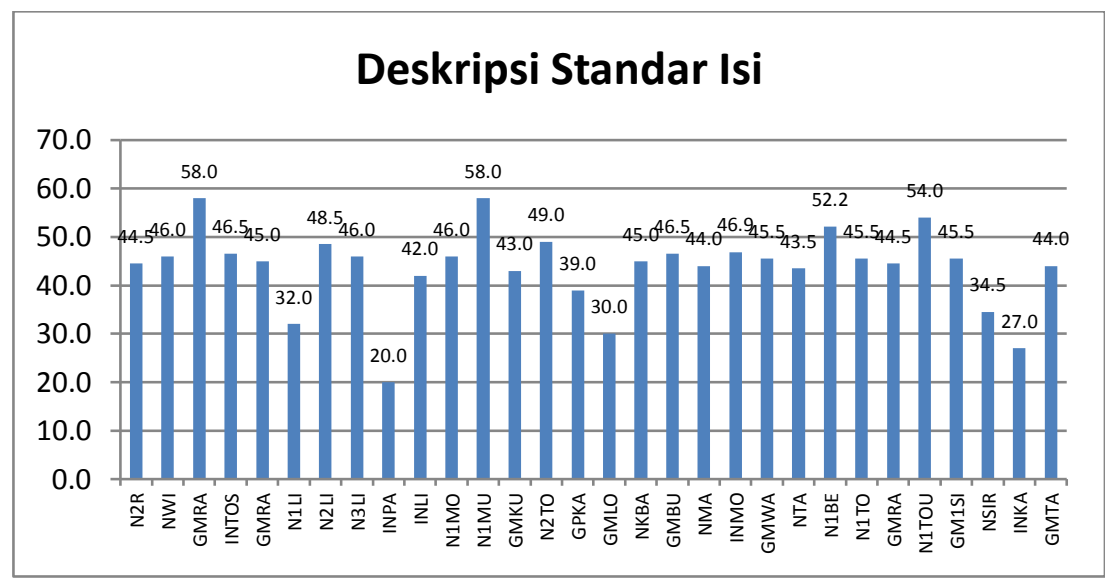

Gambar 3. Deskripsi Standar Isi Sekolah Dasar di Kabupaten Minahasa Tenggara

\subsection{Standar Proses}

Sekolah yang mempunyai nilai paling tinggi untuk standar proses adalah SD Negeri Tababo dengan nilai sebesar 23. Sedangkan sekolah dasar yang memiliki nilai standar proses paling rendah adalah SD Negeri 1 Liwutung, SD Gereja Pantekosta Kali, SD Negeri Kecil Banga, SD Negeri Maulit, SD Negeri Toundanow, SD INPRES Kali, dan SD GMIM Tambelang dengan nilai masingmasing sebesar 11 (Gambar 4).

\subsection{Standar Pendidik dan Tenaga Kependidikan}

Sekolah yang mempunyai nilai paling tinggi untuk standar Pendidik dan Tenaga Kependidikan (SPTK) adalah SD Negeri 2 Liwutung dengan nilai sebesar 88. Hal ini berarti bahwa SD Negeri Liwutung memiliki pendidik dan tenaga kependidikan paling banyak ditinjau dari segi jumlah maupun kulitasnya (Gambar 8). Sekolah yang mempunyai nilai paling rendah untuk SPTK adalah SD GMIM Bunag dengan nilai sebesar 19. Dengan kata lain bahwa SD Negeri Bunag memiliki paling sedikit jumlah dan kualitas Tenaga Pendidik dan Tenaga Kependidikan (Gambar 5).

\subsection{Standar Sarana dan Prasarana}

Sekolah yang mempunyai nilai paling tinggi untuk standar Sarana dan Prasarana (SSP) adalah SD GMIM Bunag dengan nilai sebesar 7.220. Hal ini disebakan karena sekolah ini memiliki lahan yang sangat luas yaitu $3770 \mathrm{~m}^{2}$. Sekolah yang mempunyai nilai paling rendah untuk SSP adalah SD GMIM 1 Silian Raya. (Gambar 6). 


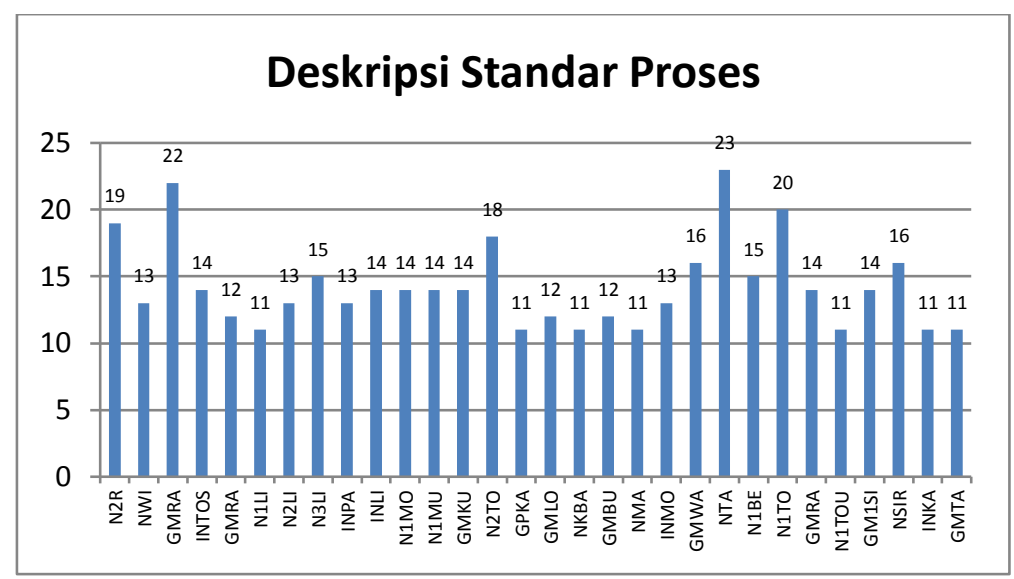

Gambar 4. Deskripsi Standar Proses Sekolah Dasar di Kabupaten Minahasa Tenggara

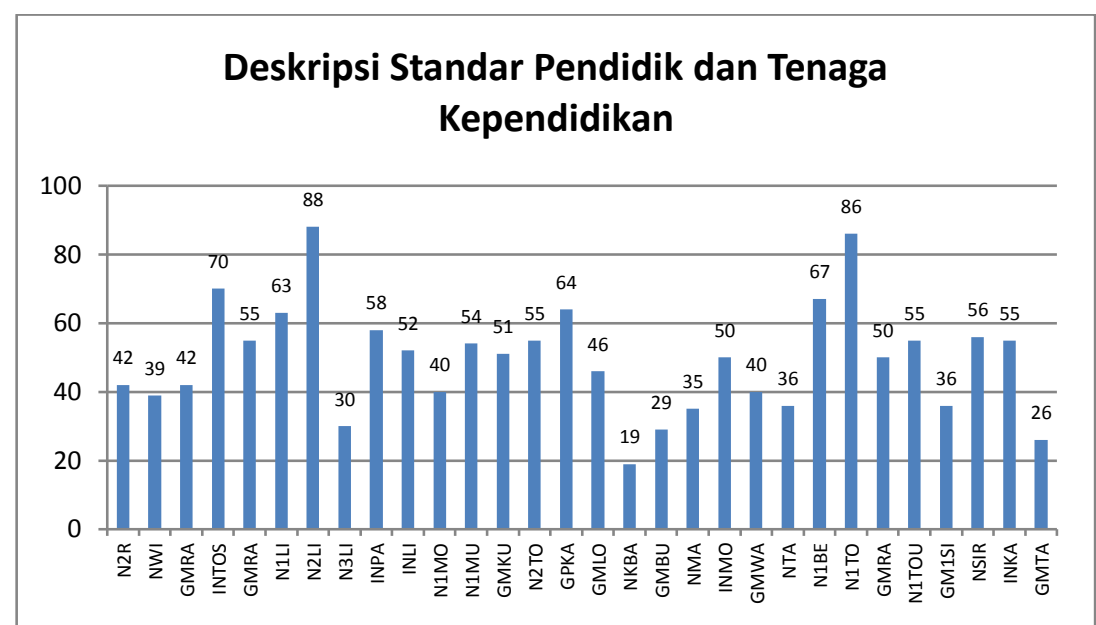

Gambar 5. Deskripsi Standar Pendidik dan Tenaga Kependidikan Sekolah Dasar di Kabupaten Minahasa Tenggara

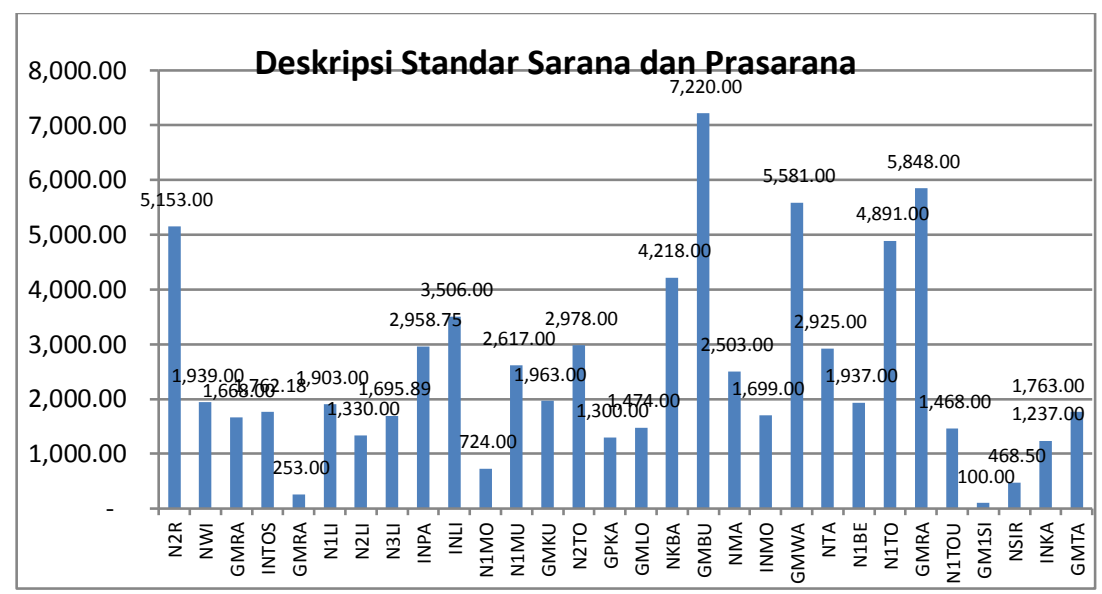

Gambar 6. Deskripsi Standar Sarana dan Prasarana Sekolah Dasar di Kabupaten Minahasa Tenggara

\subsection{Standar Pengelolaan}

SD GMIM Ratahan memiliki nilai standar pengelolaan (SPENG) tertinggi dengan nilai sebesar 249. Hal ini berarti bahwa SD GMIM Ratahan memiiki manajemen pengelolaannya paling baik di Kabupaten Minahasa Tenggara. Sekolah yang mempunyai nilai paling rendah untuk standar 
pengelolaan adalah SD GMIM Lobu dengan nilai sebesar 110. Hal ini berarti bahwa SD GMIM Lobu manajemen pengelolaannya paling buruk (Gambar 7).

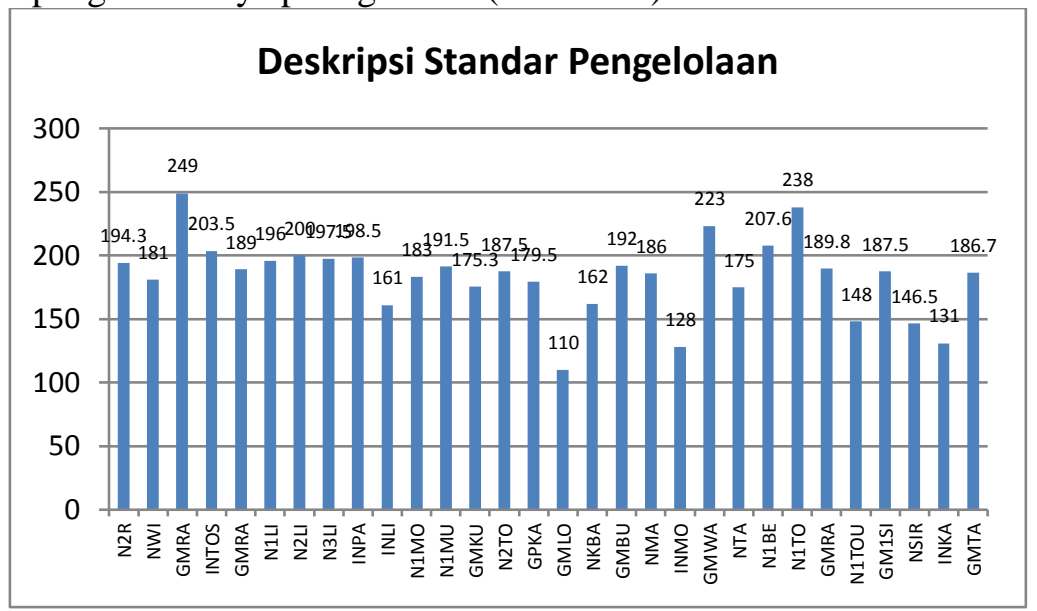

Gambar 7. Deskripsi Standar Pengelolaan Sekolah Dasar di Kabupaten Minahasa Tenggara

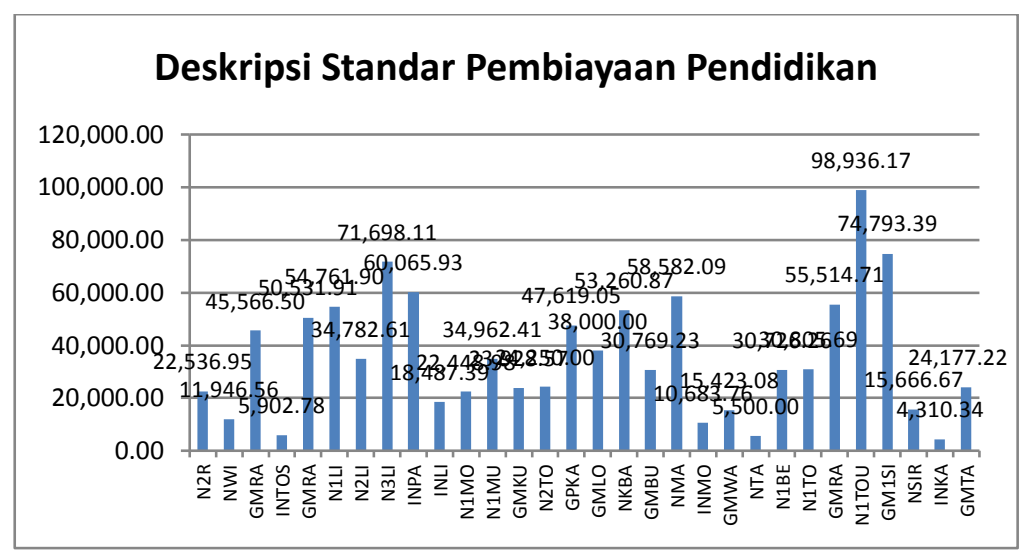

Gambar 8. Deskripsi Standar Pembiayaan Pendidikan Sekolah Dasar di Kabupaten Minahasa Tenggara

\subsection{Standar Pembiayaan Pendidikan}

SD Negeri 1 Toundanow memiliki nilai standar pembiayaan pendidikan tertinggi dengan nilai sebesar 98.936,17. Sekolah yang mempunyai nilai paling rendah untuk standar pembiayaan pendidikan adalah SD Inpres Kali dengan nilai sebesar 4.310,34 (Gambar 8).

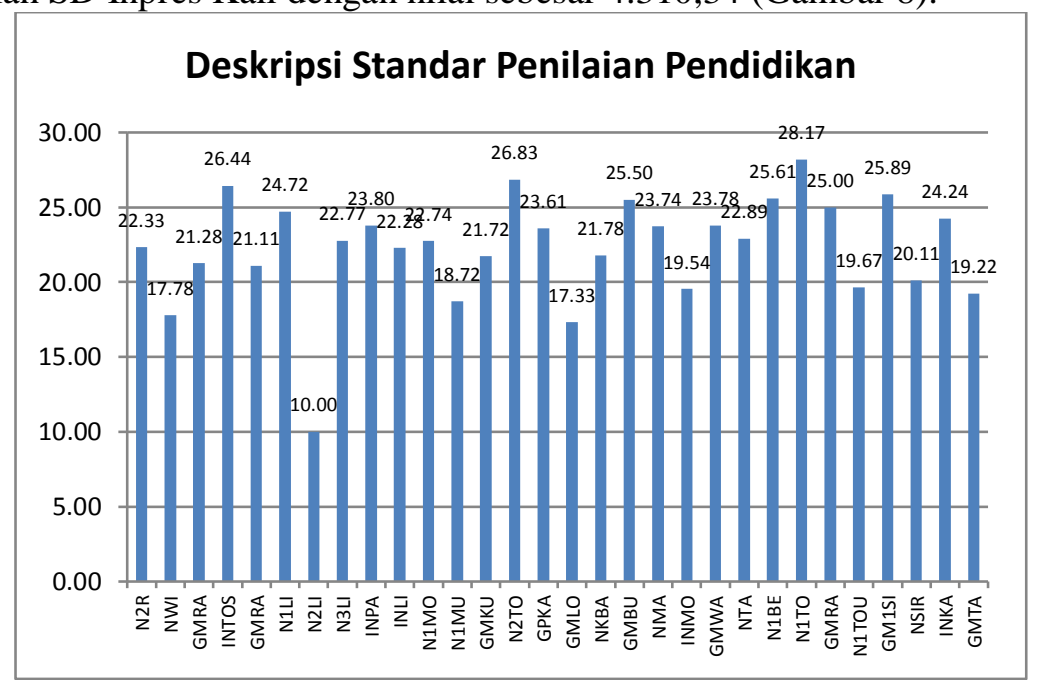

Gambar 9. Deskripsi Standar Penilaian Pendidikan Sekolah Dasar di Kabupaten Minahasa Tenggara 


\subsection{Standar Penilaian Pendidikan}

Gambar 9 menunjukkan standar penilaian pendidikan (SPNP) dari Sekolah Dasar di Kabupaten Minahasa Tenggara. SD Negeri 1 Tombatu memiliki nilai standar penilaian pendidikan paling baik dengan nilai sebesar 28,17. Hal ini berarti bahwa SD Negeri 1 Tombatu memiiki standar penilaian paling baik di Kabupaten Minahasa Tenggara. Sekolah yang mempunyai nilai paling rendah untuk standar penilaian pendidikan adalah SD Negeri 2 Liwutung dengan nilai sebesar 10.

\subsection{Analisis Biplot}

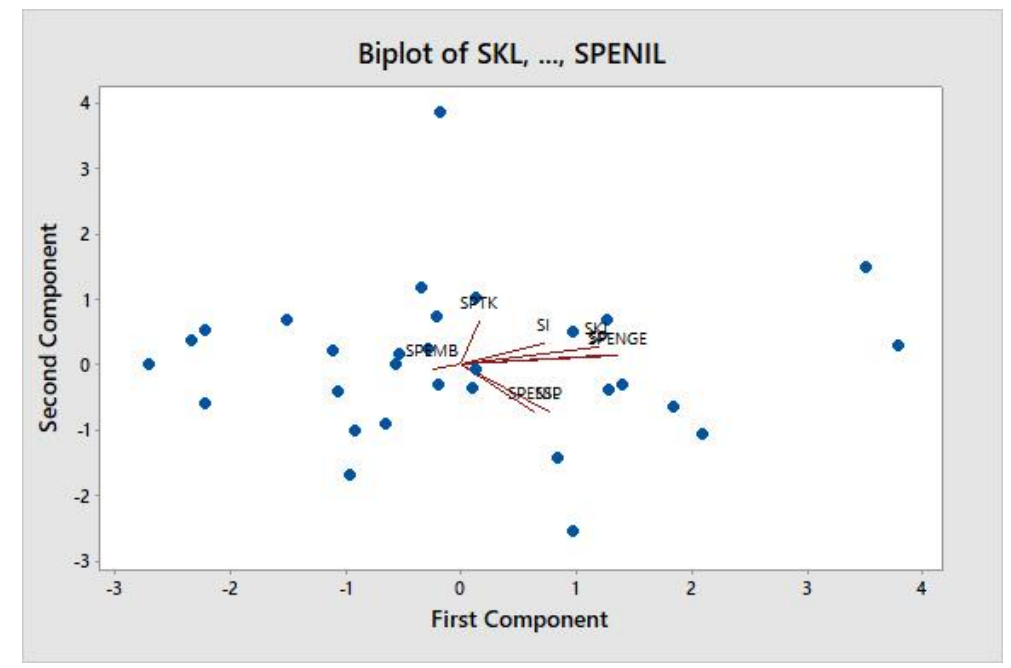

Gambar 10. Analisis Biplot Sekolah Dasar di KabupatenMinahasa Tenggara Berdasarkan Indikator Standar Nasional Pendidikan

Standar pengelolaan (X6) memiliki keragaman terbesar karena memiliki vektor yang paling panjang. Hal ini menunjukkan bahwa SD di Kabupaten Minahasa Tenggara memiliki pengelolaan yang sangat bervariasi antara satu sekolah dengan sekolah lainnya. Standar lain yang memiliki keragaman besar adalah standar kompetensi lulussan (X1).

Standar pembiayaan pendidikan (X7) memiliki keragaman yang paling kecil karena panjang vektornya relatif sama dan paling pendek. Hal ini menunjukkan bahwa pembiayaan pendidikan SD Kabupaten Minahasa Tenggara relatif sama antara satu sekolah dengan sekolah lainnya (Gambar 10).

SD Inpres Tombatu, SD Negeri 1 Belang dan SD GMIM Ratahan memiliki standar isi dan standar kompetensi lulusan (X1) yang berjalan dengan baik. SD GMIM 1 Silian memiliki standar penilaian pendidikan (X8) dan standar sarana dan prasarana (X5) yang baik. SD GMIM Ratahan, SD Negeri 1 Tombatu, SD Negeri 2 Tombatu, SD Negeri Tababo, SD Negeri 2 Ratahan dan SD GMIM Watuliney memiliki standar pengelolaan (X6) dan standar proses yang berjalan dengan baik (Gambar 10).

Gambar 10 menunjukkan SD Negeri 3 Liwutung, SD GMIM Ranoketang memiliki standar penilaian pendidikan (X8) serta standar sarana dan prasarana (X5) yang baik. Sekolah-Sekolah Dasar yang memiliki pembiayaan (X7) yang baik adalah SD GMIM Kuyanga, SD GMIM Tambelang, SD Negeri 1 Molompar, SD Inpres Liwutung, SD Gereja Pantekosta Kali, SD Negeri 1 Liwutung, SD Negeri Maulit, SD Inpres Pangu dan SD Inpres Kali. SD Negeri 2 Liwutung, SD Inpres Tosuraya, SD GMIM Rasi dan SD Negeri Wioi memiliki tenaga pendidik dan kependidikan yang baik.

Sekolah-sekolah dasar yang tidak memuhi Standar Nasional Pendidikan, yaitu: SD GMIM Bunag, SD Negeri Kecil Banga, SD Inpres Molompar, SD GMIM Lobu, SD Negeri 1 Toundanow dan SD Negeri Silian Raya.

\subsection{Analisis Regeresi Linier Berganda}

Dengan menggunakan analisis regresi linier berganda diperoleh hasil sebagai berikut: 


\begin{tabular}{|c|c|c|c|c|c|c|}
\hline \multirow{2}{*}{\multicolumn{2}{|c|}{ Model }} & \multicolumn{2}{|c|}{ Unstandardized Coefficients } & \multirow{2}{*}{$\begin{array}{c}\begin{array}{c}\text { Standardized } \\
\text { Coefficients }\end{array} \\
\text { Beta }\end{array}$} & \multirow[b]{2}{*}{$\mathrm{t}$} & \multirow[b]{2}{*}{ Sig. } \\
\hline & & $\mathrm{B}$ & Std. Error & & & \\
\hline \multirow{9}{*}{1} & (Constant) & 96.206 & 23.195 & & 4.148 & .001 \\
\hline & SKL & -.643 & .800 & -.313 & -.804 & .435 \\
\hline & SI & -.026 & .146 & -.051 & -.175 & .863 \\
\hline & SP & .420 & .453 & .331 & .926 & .370 \\
\hline & SPTK & .103 & .076 & .365 & 1.354 & .197 \\
\hline & SSP & $-7.258 \mathrm{E}-5$ & .001 & -.028 & -.101 & .921 \\
\hline & SPNG & .033 & .073 & .217 & .454 & .657 \\
\hline & SPEMP & $5.378 E-5$ & .000 & .269 & .892 & .388 \\
\hline & SPENP & -.301 & .290 & -.268 & -1.036 & .318 \\
\hline
\end{tabular}

Hasil menunjukkan bahwa model yang bisa digunakan untuk memprediksi nilai akreditasi (mutu pendidikan) SD di kabupaten Minahasa Tenggara adalah:

AKRED $=96.206-0.643 \mathrm{X} 1-0.026 \mathrm{X} 2+0.42 \mathrm{X} 3+0.103 \mathrm{X} 4-0.00007 \mathrm{X} 5$

$+0.33 \times 6+0.00005 \times 7-3.01 \times 8$

\section{Kesimpulan}

1. Berdasarkan grade akreditasi, terdapat 9 (30\%) Sekolah Dasar (SD) terakreditasi A, 14 SD (46,67\%) terakreditasi B dan yang belum terakreditasi sebesar 23,33\% atau 7 SD. SDN 1 Liwutung mempunyai nilai akreditasi sebesar 91 yang merupakan nilai tertinggi di Kabupaten Minahasa Tenggara.

2. SD GMIM Ratahan memiliki skor tertinggi pada standar kompetensi lulusan, standar isi dan standar pengelolaan. SD Negeri 1 Mundung memiliki skor tertinggi pada standar isi. SD Negeri 2 Liwutung memiliki skor tertinggi pada standar pendidik dan tenaga kependidikan. Sedangkan SD Negeri 1 Tababo, SD GMIM Bunag, SD Negeri 1 Tondanouw, dan SD Negeri 1 Tombatu memiliki nilai tertinggi masing-masing untuk standar proses proses, standar sarana dan prasarana, standar pembiayaan pendidikan serta standar penilaian pendidikan.

3. Model untuk memprediksi nilai akreditasi SD di Kabupaten Minahasa Tenggara adalah: AKRED $=96.206-0.643 \mathrm{X} 1-0.026 \mathrm{X} 2+0.42 \mathrm{X} 3+0.103 \mathrm{X} 4-0.00007 \mathrm{X} 5+0.33 \mathrm{X} 6+$ $0.00005 \times 7-3.01 \times 8$.

\section{Daftar Pustaka}

[1] Hatidja, D. 2010. Analisis Biplot Terhadap Mutu Pendidikan SMA-SMA di Kota Manado. Jurnal Ilmiah Sains, 10(1).

[2] Hatidja, D. dan R. Take. 2012. Pemetaan SMP-SMP di Kab. Minahasa Tenggara Berdasarkan Standar Kompetensi Lulusan, Standar Isi dan Standar Proses. Prosiding Seminar Nasional Matematika XVI, Bandung 3-6 Juli 2012.

[3] Daman, R. dan D. Hatidja. 2012. Pemetaan SMP-SMP di Kab. Minahasa Tenggara Berdasarkan Standar Pendidikan dan Tenaga Kependidikan, Standar Sarana dan Prasarana, Standar Pengelolaan, dan Standar Pebiayaan Menggunakan Analisis Biplot. Jurnal De Cartesian 1(1).

[4] Hatidja, D., Ch. Purwanto, dan M. Paendong. 2015. Pemetaan SMA/SMK Di Kabupaten Minahasa Tenggara Berdasarkan Empat Indikator Standar Nasional Pendidikan Dengan Menggunakan Analisis Biplot. Prosiding Seminar Nasional Matematika Tahun 2015, UNPAD Bandung, 6 Juni 2015.

[5] Sepang, M.Z., D. Hatidja, dan Y. Langi. 2015. Pemetaan SMA dan SMK Berdasarkan Standar Kompetensi Lulusan, Proses, Pembiayaan Pendidikan, dan Penilaian Pendidikan Menggunakan Analisis Biplot di Kabupaten Minahasa Tenggara. Jurnal De Cartesian 4(1). 
[6] Peraturan Pemerintah Republik Indonesia Nomor 19 Tahun 2005 tentang Standar Nasional Pendidikan.

[7] Simamora, B. 2005. Analisis Multivariat Pemasaran. PT Gramedia Pustaka Utama, Jakarta.

[8] Johnson, R. A and D. Wichern. 2005. Applied Multivariate Statistical Analysis. Fifth Edition. Prentice Hall Inc., USA.

[9] Dillon, W. R., and M. Goldstein. 1984. Multivariate Analysis of Method and Application. John Wiley \& Sons, New York.

[10] Gabiel, K.R. 1971. The Biplot Graphic Display of Matrices with Application to Principal Component Analysis. Biometrika 58(3), pp. 453.

[11] Jollife, I. T. 1986. Principle Component Analysi. Springer Verlag, New York.

[12] Mattjik, A.A., M, Sumertajaya, H, Wijayanto, Indahwati, A, Kurnia, B, Sartono. 2004. Modul Teori Pelatihan Analisis Multivariat. Departemen Statistika FMIPA IPB, Bogor.

[13] Everit, B. 1978. Graphical Techniques for Multivariate Data. Heinemann Educational Books.

[14] Myers, R.H. 1990. Classical and Modern Regression with Applications. PWS-KENT Publishing Company. Boston. 